\title{
A DISPENSA COLETIVA TRABALHISTA À LUZ DOS DEVERES DE SOCIALIDADE E ETICIDADE DOS CONTRATOS.
}

\author{
Maurício de Melo Teixeira Branco ${ }^{1}$
}

\section{RESUMO}

O presente artigo analisa a nova redação conferida ao texto da CLT, em seu artigo 477-A, para discutir a aplicação dos princípios de eticidade e socialidade ao encerramento dos contratos de trabalho. Defende que o encerramento unilateral do contrato de trabalho pelo empregador corresponde a rediscussão do contrato de trabalho. Conclui que não se pode, no ordenamento brasileiro, permitir que a dispensa coletiva ocorra sem a intervenção dos sindicatos.

Palavras-chave: Dispensa coletiva. Boa-fé. Função social.

\section{MASS DISMISSAL IN BRAZIL UNDER PRINCIPLES OF SOCIALITY AND GOOD- FAITH.}

\begin{abstract}
This article analyzes the text of the CLT, in its article 477-A, to discuss the application of the principles of ethics and sociality to the termination of employment contracts. It argues that the unilateral termination of the employment contract by the employer corresponds to a rediscussion of the employment contract. It concludes that it is not possible, in the Brazilian law, to allow the mass dismissal without collective agreement.
\end{abstract}

Keywords: Mass dismissal. Good-faith. Sociality.

\section{INTRODUÇÃO}

A disciplina do encerramento do vínculo empregatício é dos temas que mais desperta discussões no âmbito do Direito do Trabalho. Sem qualquer dúvida, as hipóteses de extinção unilateral dos contratos são as que encerram maior controvérsia, diante da necessidade de promover o equilíbrio entre a autorização ao exercício regular de um direito, ao mesmo tempo em que se busca resguardar os contratantes dos efeitos irregulares decorrentes de seu abuso.

Por atingir uma coletividade de trabalhadores, o tema da despedida em massa sempre foi alvo de especial consideração. Segundo Orlando Gomes (1974, p. 575), a dispensa coletiva é a "rescisão simultânea, por motivo único, de uma pluralidade de contratos de trabalho numa empresa, sem substituição dos empregados dispensados".

Luciano Martinez (2016, p. 651) segue a mesma definição, ao conceituar como a que é “operada simultaneamente, por motivo único, contra um grupo de trabalhadores, sem

\footnotetext{
${ }^{1}$ Advogado, graduado (2006) e mestre (2009) pela Universidade Federal da Bahia. Professor Substituto da UFBA, da Unijorge e da Unifacs. Membro do Instituto Bahiano de Direito do Trabalho.
}

Rev. do Dir. do Trabalho e Meio Ambiente do Trabalho | e-ISSN: 2525-9857 | Salvador | v. 4 | n. 1 | p. 98 - 
pretensão de substituição dos dispensados".

Em 2009, em virtude do grave impacto social das despedidas havidas na Embraer, a jurisprudência convencionou que este ato deveria ser precedido por negociação coletiva, por meio de decisão da Seção de Dissídios Coletivos do TST, sob a relatoria do Ministro Maurício Godinho Delgado, cuja ementa aqui se transcreve:

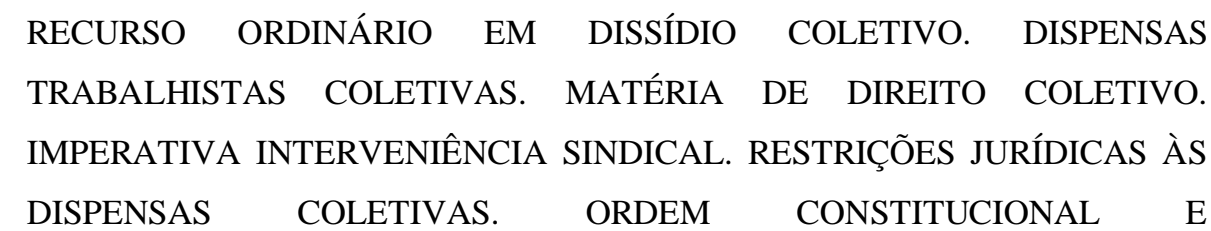
INFRACONSTITUCIONAL DEMOCRÁTICA EXISTENTE DESDE 1988.

[...]Na vigência da Constituição de 1988, das convenções internacionais da OIT ratificadas pelo Brasil relativas a direitos humanos e, por consequência, direitos trabalhistas, e em face da leitura atualizada da legislação infraconstitucional do país, é inevitável concluir-se pela presença de um Estado Democrático de Direito no Brasil, de um regime de império da norma jurídica (e não do poder incontrastável privado), de uma sociedade civilizada, de uma cultura de bem-estar social e respeito à dignidade dos seres humanos, tudo repelindo, imperativamente, dispensas massivas de pessoas, abalando empresa, cidade e toda uma importante região. Em consequência, fica fixada, por interpretação da ordem jurídica, a premissa de que 'a negociação coletiva é imprescindível para a dispensa em massa de trabalhadores'.

(TST, ED-RODC - 30900-12.2009.5.15.0000, Data de Publicação: DEJT 04/09/2009)

Por meio do julgado em questão, restou fixado pelo TST como premissa que as despedidas coletivas não se equiparam às despedidas individuais, razão pela qual as primeiras exigem serem precedidas por negociação coletiva. Tal entendimento restou largamente aplicado pelos demais Tribunais trabalhistas, sendo possível destacar como exemplo a decisão do TRT da $1^{\text {a }}$ Região no julgamento da despedida ocorrida na Webjet, dentre outros julgados mais recentes.

A despeito do tema ter sido considerado como já superado pela jurisprudência, a inovação trazida pela Lei 13.467/2017 (Reforma Trabalhista), que adicionou ao texto da Consolidação das Leis do Trabalho o artigo 477-A reinaugurou os debates sob a matéria.

Tal decorre do fato de que o novo dispositivo possui redação em sentido diametralmente contrário ao posicionamento anteriormente solidificado pelo TST:

Art. 477-A. As dispensas imotivadas individuais, plúrimas ou coletivas equiparamse para todos os fins, não havendo necessidade de autorização prévia de entidade sindical ou de celebração de convenção coletiva ou acordo coletivo de trabalho para sua efetivação.

Rev. do Dir. do Trabalho e Meio Ambiente do Trabalho | e-ISSN: 2525-9857 | Salvador | v. 4 | n. 1 | p. 98 118 | Jan/Jun. 2018 
$\mathrm{Na}$ esteira do novo texto legislativo, observou-se o encerramento coletivo de contratos, por ato do empregador, sem a realização de negociação coletiva precedente, fatos amplamente divulgados pela imprensa nacional. Como exemplo, é possível citar a despedida de 1.200 professores do grupo de ensino superior Estácio, divulgada em 05.12.2017², além de diversos outros atos no mesmo sentido.

Em face do dissenso interpretativo, a matéria restou judicializada, sendo observada a alternância de decisões ora autorizando, ora vedando a conduta do empregador. Ao fim, observa-se que, julgando Reclamação Correcional em face de decisões da Justiça do Trabalho, o atual Presidente do TST avocou para si a posição final sobre a matéria, como se infere das seguintes decisões recentes proferidas pelo Ministro Ives Gandra Martins Filho:

Quanto à situação excepcional de abuso, este se encontra no impedimento ao exercício do direito potestativo de dispensa, desde que pagas as verbas rescisórias devidas, invocando, para se exigir a negociação coletiva prévia com o sindicato em face do número de empregados dispensados, decisão judicial superada tanto pela lei quanto pela própria jurisprudência pacificada do TST, causando gravame substancial à Requerente, dada a limitação temporal para dispensa de professores, na "janela" dos meses de julho e dezembro. A hipótese é de nítido ativismo judiciário, contrário ao pilar básico de uma democracia, da separação entre os Poderes do Estado. Com efeito, em que pese por décadas, desde que a Constituição Federal de 1988 foi editada, demissões plúrimas se darem, apenas em 2009, em precedente da SDC, calcado em princípios gerais constitucionais, é que se passou a exigir, mesmo sem lei específica, a negociação coletiva prévia às demissões plúrimas. Ou seja, por mais de 20 anos teríamos convivido com essa inconstitucionalidade de conduta patronal. E mais. Em nítido reconhecimento do ativismo judiciário que se praticava, o precedente da SDC registrou que a orientação apenas se adotaria nos próximos dissídios coletivos de natureza jurídica ajuizados com esse objeto, como se lei fosse. Cite-se, por oportuno, trecho do referido precedente, verbis:

$[\ldots]$

Justamente para fazer frente a tal precedente é que o legislador ordinário deixou expresso, na reforma trabalhista veiculada pela Lei 13. 467/17, no art. 477-A da CLT, que as demissões plúrimas prescindem de negociação coletiva prévia, verbis: "Art. 477-A. As dispensas imotivadas individuais, plúrimas ou coletivas equiparamse para todos os fins, não havendo necessidade de autorização prévia de entidade sindical ou de celebração de convenção coletiva ou acordo coletivo de trabalho para sua efetivação" (grifos nossos). Não bastasse tanto, a própria jurisprudência da SDC foi revista pelo Pleno do TST, sendo superada em precedente que não admite

\footnotetext{
${ }^{2} \mathrm{O}$ endereço eletrônico da referida notícia se encontra nas referências.
} 
dissídio coletivo de natureza jurídica para discutir demissões plúrimas, nos quais se firmara a tese da exigência de negociação coletiva, em interpretação de nosso ordenamento jurídico trabalhista (cfr. TST-RO-10782-38.2015.5.03.0000, Red. Min. Maria Cristina Peduzzi, julgado em 18/12/17, com acórdão ainda não publicado). Convém registrar que a própria tese de fundo não deixou de ser levantada no julgamento plenário, ainda que obiter dictum, ou seja, sem fixação de entendimento da Corte, com os ministros que acompanharam a divergência da redatora designada para o acórdão se perfilando, en passant, pela aplicação da lei nova ao caso, lembrando que agora legem habemus. [...]

(TST. CorPAr-1000011-60.2018.5.00.0000. Relator: Ministro Ives Gandra Martins Filho, DJT 11.01.2018)

Com a devida vênia, em que pesem os sólidos argumentos expendidos na referida decisão, opina-se que o posicionamento atual adotado pelo TST não deve ser mantido, uma vez que o entendimento anterior se encontrava em maior conformidade ao ordenamento jurídico. É o que se pretende demonstrar com esse artigo.

\section{Comentários ao processo legislativo que deu origem ao artigo 477-A da CLT.}

Da análise do decisum oriundo da Presidência do TST, observa-se que a crítica ao ativismo judicial possui papel de destaque, razão pela qual se aproxima do pensamento de Estevão Mallet (2017, p. 123-142) sobre o tema, em artigo publicado na respeitada Revista da Faculdade de Direito da USP.

No texto em questão, o professor discorre sobre o contexto em que foi proferida a decisão paradigmática da SDC, para sustentar que sua aprovação por apertada maioria, somado ao fato de que os argumentos expendidos não teriam efetiva densidade, para concluir pela impossibilidade de exigir a negociação coletiva prévia à dispensa coletiva.

Partindo das mesmas observações anteriormente tecidas por Estevão Mallet, a decisão da presidência do TST destaca o efeito normativo oriundo da aprovação da Lei 13.467/2017 ('agora legem habemus'), para o qual chama atenção ao efeito expresso da vontade legislativa de superar o precedente da SDC.

Cumpre destacar que não se concorda em nenhum ponto com a referida argumentação, posto que os princípios indicados na decisão anterior também são normas jurídicas positivas no ordenamento pátrio. Talvez o mais correto seria apontar que agora existe "regra" a disciplinar o tema. 
Não se pode deixar de notar, todavia, que a alteração legislativa é justificada como principal fundamento para a mudança no posicionamento jurisprudencial do TST. Em que pese aqui não se pretenda discutir a validade formal da Lei 13.467/2017, considera-se importante analisar o processo de gênese do atual artigo 477-A da CLT, para demonstrar que materialmente o processo de aprovação do seu texto não é capaz de afastar a discussão sobre sua legitimidade.

Na Câmara dos Deputados, o Projeto de Lei 6787/2016, que futuramente se tornaria a Lei 13.467/2017, recebeu nada menos que 1340 emendas, apresentadas por diversos parlamentares.

Compulsando a tramitação do referido Projeto de Lei, observa-se que coube ao Deputado Federal Jerônimo Goergen (PP/RS) propor a criação do parágrafo $9^{\circ}$ ao artigo 477 da CLT, com o texto que posteriormente foi renumerado para artigo 477-A. O dispositivo em comento foi apresentado por meio de Emenda na Comissão 491, em 21.03.2017, com a seguinte fundamentação:

Assegurar a igualdade para os empregados e para as empresas nas dispensas individual, plúrima ou coletiva. Esclarece em lei que os empregados possuem direitos iguais na rescisão imotivada do contrato de trabalho, independentemente da modalidade da dispensa: individual, plúrima ou coletiva.

A distinção, que vinha crescendo na jurisprudência antes da crise econômica, tratava de forma desigual os empregados nos processos de dispensa coletiva, com a obrigatoriedade de negociação com vantagens adicionais para rescisão contratual. Além disso, a legislação estabelece quais as verbas rescisórias devem ser pagas e também regula o seguro-desemprego e o saque na conta vinculada ao FGTS. A crise mostrou que a medida é inadequada, também sob o ponto de vista da atividade econômica, pois milhares de empresas poderiam estar fechadas e outras sem o capital necessário para a retomada, se essa jurisprudência tivesse sido aplicada nos últimos anos. Logo, a medida teria potencial para ampliar o número já expressivo de desempregados no país, que já atingiu o marco de mais de 12 milhões em 2017, índice sem antecedentes no Brasil nos últimos cinco anos.

O texto acima corresponde à integralidade da exposição de motivos apresentada na sugestão normativa que veio a se tornar o dispositivo em questão. Em verdade, se é possível questionar a decisão da SDC de 2009 por remeter a dispositivos gerais da Constituição, não se mostra muito razoável que o único argumento jurídico a embasar a proposta seja justamente a isonomia, em sentido apenas formal, sob a tese de que todos os trabalhadores teriam o mesmo direito a ser dispensados sob um único procedimento, independente da modalidade. Trata-se de estranha hipótese de isonomia in pejus, para a qual não se identifica precedente. 
Ora, chama-se atenção de que é a isonomia, em sentido material, que justifica a existência do dever de proteção da parte hipossuficiente da relação individualmente considerada. Por sua vez, é a participação do sindicato, no âmbito coletivo, que garante à autonomia privada força normativa, sob o aspecto da equivalência dos contratantes coletivos.

A despeito da indicação de Autoria pelo citado deputado, a mesma proposta foi também apresentada pelo Deputado Federal Alfredo Kaefer (PSL/PR) por meio da Emenda na Comissão 699, em 22.03.2017:

Assegurar a igualdade para os empregados e para as empresas nas dispensas individual, plúrima ou coletiva Esclarece em lei que os empregados possuem direitos iguais na rescisão imotivada do contrato de trabalho, independentemente da modalidade da dispensa: individual, plúrima ou coletiva. A distinção, que vinha crescendo na jurisprudência antes da crise econômica, tratava de forma desigual os empregados nos processos de dispensa coletiva, com a obrigatoriedade de negociação com vantagens adicionais para rescisão contratual. Além disso, a legislação estabelece quais as verbas rescisórias devem ser pagas e também regula o seguro-desemprego e o saque na conta vinculada ao FGTS. A crise mostrou que a medida é inadequada, também sob o ponto de vista da atividade econômica, pois milhares de empresas poderiam estar fechadas e outras sem o capital necessário para a retomada, se essa jurisprudência tivesse sido aplicada nos últimos anos. Logo, a medida teria potencial para ampliar o número já expressivo de desempregados no país, que já atingiu o marco de mais de 12 milhões em 2017, índice sem antecedentes no Brasil nos últimos cinco anos.

Embora não se exija originalidade das propostas legislativas, não deixa de ser curioso que dois parlamentares distintos apresentem exatamente a mesma sugestão normativa, com exatamente a mesma exposição de motivos. Ainda assim, tal não tem o condão de invalidar o texto de Lei aprovado, malgrado as duas Emendas tenham sido individualmente aprovadas pela Comissão, como se fossem distintas.

Todavia, se a discussão recair sobre a legitimação da norma em questão, não será possível deixar de notar que o texto das duas emendas, por sua vez, corresponde à exata redação que consta da Revista Via Juris (2017), publicada no site do Instituto Via Juris anteriormente à apresentação das propostas, com diversas sugestões de alteração do texto da CLT:

ASSEGURAR A IGUALDADE PARA OS EMPREGADOS E PARA AS EMPRESAS NAS DISPENSAS INDIVIDUAL, PLÚRIMA OU COLETIVA Esclarece em lei que os empregados possuem direitos iguais na rescisão imotivada do contrato de trabalho, independentemente da modalidade da dispensa: individual, 
plúrima ou coletiva. A distinção, que vinha crescendo na jurisprudência antes da crise econômica, tratava de forma desigual os empregados nos processos de dispensa coletiva, com a obrigatoriedade de negociação com vantagens adicionais para rescisão contratual. Além disso, a legislação estabelece quais as verbas rescisórias devem ser pagas e também regula o segurodesemprego e o saque na conta vinculada ao FGTS. A crise mostrou que a medida é inadequada, também sob o ponto de vista da atividade econômica, pois milhares de empresas poderiam estar fechadas e outras sem o capital necessário para a retomada, se essa jurisprudência tivesse sido aplicada nos últimos anos.

Na revista em questão, para além da fundamentação, se encontra também a expressa sugestão de criação de artigo de Lei, com o mesmo texto do novel 477-A, na Revista apresentada como 477, parágrafo $9^{\circ}$, que é como constou das Emendas.

No mesmo site do Instituto Via Juris, consta também que o Deputado Federal relator da Comissão Especial da Reforma Trabalhista, Roberto Marinho (PSDB-RN) teria recebido um exemplar da publicação em questão no dia 04.04.2017 (INSTITUTO VIA JURIS, 2017).

Frise-se: não há vedação legal de que cidadãos apresentem a parlamentares sugestões normativas. No entanto, considerando a relevância do tema aqui discutido, é importante notar que não foi identificado (sequer na publicação) quem seria o autor intelectual da proposta.

Considerando as particularidades do processo legislativo brasileiro, não se exige dos representantes do povo que suas propostas se moldem à visão doutrinária e jurisprudencial dos Tribunais sobre um tema. Quando oriunda da criação do parlamentar, a proposta deve refletir basicamente a ideologia esposada pelo mesmo, bem como aderência a suas propostas eleitorais.

Da mesma forma, é de se imaginar que uma Emenda parlamentar seja alvo de críticas e divergências por outros parlamentares. A sua aprovação, após debates, talvez seja a principal fonte de sua legitimação social. Como era de se esperar, a proposta legislativa apresentada foi alvo de pedido de alterações e supressões.

Mas é absolutamente singular observar que a maior oposição à criação do dispositivo em questão tenha partido do Deputado Federal Jerônimo Goergen (PP/RS). Curiosamente, o próprio Autor da proposta de redação do dispositivo em questão se tornou seu maior e melhor opositor, trazendo em 18.04.2017 a, com pedido de supressão do artigo por ele apresentado.

A análise da exposição de motivos da Emenda ao Substitutivo 27 aparentemente filia o parlamentar aos fundamentos trazidos pela SDC do TST, entendendo que o texto atualmente vigente contraria até mesmo a lógica que conduzia a toda a Reforma Trabalhista na Comissão: 
É cediço que as demissões coletivas, mais que as demissões pontuais, são fatores que causam enorme instabilidade a todos os envolvidos, além de serem traumáticas para todos aqueles que atravessam a experiência. As demissões em massa impactam não somente trabalhadores e empresas, mas acabam por atingir a sociedade como um todo. Desde o abalo à economia, até, por vezes, o severo comprometimento da saúde de cidades, como nos casos de encerramento das atividades de uma empresa que emprega parte considerável da população daquela localidade. A busca para esta inovação legislativa certamente originou-se de tentativa de esquivo às tendências jurisprudências que fixaram a necessidade de negociação prévia, entre empresa e sindicato, ante à necessidade de dispensa coletiva. Da forma tal como se encontra, além de desconsiderar a severidade dos impactos sociais e econômicos decorrentes, parece-nos que o Legislador pretendeu limitar e interferir em direito constitucional assegurado aos sujeitos envolvidos em negociações coletivas. Inexiste, no ordenamento jurídico atual, qualquer lei ou determinação que limite ou cerceie os objetos das negociações coletivas, muito pelo contrário, até reduções salariais poderão ser objetos destas negociações. Por mais esta razão, soa desarrazoável e indefensável a alteração pretendida, afinal, a negociação visa, tão somente, conferir equilíbrio à relação de trabalho. A inserção do texto, em última análise, constitui retrocesso ao sistema democrático e da mínima intervenção do Estado nas relações privadas, fato que saí na contramão de toda reforma trabalhista.

Se tal for possível sem violação do dever de coerência, concorda-se com a crítica feita pelo Deputado Federal Jerônimo Goergen (PP/RS) ao 'legislador', no sentido de que a redação do dispositivo de Lei visou apenas esquivar as tendências jurisprudenciais que tratavam da matéria.

E o argumento parece ter cativado outros parlamentares, visto que o Deputado Federal Goulart (PSD/SP) o utilizou para elaborar a Emenda ao Substitutivo 306, que possui a seguinte fundamentação:

É cediço que as demissões coletivas, mais que as demissões pontuais, são fatores que causam enorme instabilidade a todos os envolvidos, além de serem traumáticas para todos aqueles que atravessam a experiência. As demissões em massa impactam não somente trabalhadores e empresas, mas acabam por atingir a sociedade como um todo. Desde o abalo à economia, até, por vezes, o severo comprometimento da saúde de cidades, como nos casos de encerramento das atividades de uma empresa que emprega parte considerável da população daquela localidade. Da forma tal como se encontra o texto proposto, além de desconsiderar os impactos sociais e econômicos decorrentes, interferi em direito constitucional assegurado aos sujeitos envolvidos em negociações coletivas. Ademais, atualmente, inexiste norma ou determinação que limite ou cerceie os objetos das negociações coletivas, tendo em 
vista que a negociação visa, tão somente, conferir equilíbrio à relação de trabalho. Diante de todo o exposto, e em face da relevância social da proposta, contamos com o apoio dos nobres pares para a aprovação da presente emenda.

Com a devida vênia, a fundamentação contida no voto do ED-RODC - 3090012.2009.5.15.0000 possui maior densidade jurídica e argumentativa do que a exposição de motivos da Emenda que deu origem ao dispositivo em questão.

Merece destaque, no caso, que o fundamento para todas as propostas de alteração do texto legal remetem à jurisprudência já consolidada pelo TST acerca da matéria. É o caso da Emenda ao Substitutivo 40 apresentada pelo Deputado Federal Orlando Silva (PCdoB/SP), que conta com a seguinte exposição de motivos:

Com o acréscimo de novo artigo 477-A e B pretende-se possibilitar a demissão em massa de empregados sem a exigência de negociação coletiva com o sindicato da categoria. Na atualidade já é posicionamento do Tribunal Superior do Trabalho da vedação de dispensa imotivada em massa sem prévia negociação com o sindicato representativa da categoria dos trabalhadores. Ora, a assistência ao trabalhador foi criada para coibir práticas abusivas feitas pelo empregador, e esses artigos permitirá a demissão em massa de forma indiscriminada que vai na contramão da justificativa da reforma trabalhista que segundo seu autor pretende a criação de mais empregos. Nesse sentido, não se sustenta a alteração pretendida pelo substitutivo e conclamamos os nobres pares para aprovar a presente emenda.

O mesmo fundamento, inclusive com a mesma redação, também constou da Emenda ao Substitutivo 184, apresentada pelo Deputado Federal Hissa Abrahão (PDT/AM), assim como da Emenda ao Substitutivo 193, apresentada pelo Deputado Federal Sérgio Vidigal (PDT/ES), bem como na Emenda ao Substitutivo 259, dos Deputados Chico Alencar e Luiza Erundina (PSOL/RJ e PSOL-SP).

Talvez por esse motivo, o mesmo Deputado Federal Jerônimo Goergen (PP/RS) tenha decidido apresentar à Comissão também a Emenda ao Substitutivo 295, no qual eleva o tom das críticas, para justificar o pedido de supressão do atual artigo 477-A:

$[\ldots]$

Superadas estas especificidades pormenorizadas, não se pode olvidar de registrar que, em menor ou maior grau, algumas das alterações limitam de forma absolutamente desproporcional o direito da livre negociação das entidades sindicais, cuja maturidade negocial foi amplamente conferida com a promulgação da Constituição Federal de 1988. A título exemplificativo, menciona-se a tentativa de inserção de artigo que dispensa a negociação nos casos de demissão em massa. Trata-se de medida desproporcional e sem qualquer motivação lógica e aceitável aparente.

Rev. do Dir. do Trabalho e Meio Ambiente do Trabalho | e-ISSN: 2525-9857 | Salvador | v. 4 | n. 1 | p. 98 - 
Por outro lado, não se encontrou registro de que o texto do artigo 477-A da CLT tenha sido defendido no plenário da Câmara. Em razão da elevada celeridade conferida à tramitação do Projeto de Lei 6.787/2016, o seu texto foi encaminhado para o Senado Federal após ter tido discutida uma única alteração no substitutivo apresentado pelo relator.

No Senado, o Projeto de Lei da Câmara n. 38, de 2017, teve 864 sugestões de alteração de seu teor por meio de emendas, apresentadas por senadores de diversos partidos. Nenhuma das referidas emendas logrou ser aprovada ou discutida quanto a seu teor.

Novamente se chama atenção de que não se discute, neste trabalho, a existência do dispositivo contido no artigo 477-A da CLT. Apenas pretende-se sinalizar que a afirmação 'agora legem habemus' pode simplesmente não revelar a complexidade do processo legislativo, dentro do jogo democrático, que conduz à aprovação de uma norma.

Por outro lado, não se está buscando reduzir ou diminuir a observação feita por Estevão Mallet (2017) acerca da conveniência de conferir efeito vinculante a um julgado aprovado por "apertada maioria", cuja crítica é lúcida e pertinente. Em absoluto se postula que a atuação judicial possa substituir a produção legislativa.

Da mesma forma, a própria decisão proferida pelo Presidente do TST, Ministro Ives Gandra Martins Júnior, demonstra o quão complexa pode ser a formação de entendimento na Corte em questão. Aqui se transcreve parte de seu voto proferido nos autos do Processo $\mathrm{N}^{\mathrm{o}}$ 1000393-87.2017.5.00.0000:

In casu", para impedir a utilização, pelo empregador, do direito potestativo de dispensa sem justa causa, a autoridade coatora e a autoridade requerida, contra expresso texto de lei, exigiram o que a lei expressamente dispensa, que é a intermediação negocial do sindicato de classe para as demissões ditas de massa. Com efeito, o art. 477-A da CLT, bem como decisão do Pleno do TST (cfr. TSTRO-10782-38.2015.5.03.0000, Red. Min. Maria Cristina Peduzzi, julgado em 18/12/17), vieram a superar a orientação da SDC do TST, que exigia a negociação coletiva prévia à demissão em massa.

Malgrado até a presente data não seja possível ter acesso ao teor do julgado proferido no RO-10782-38.2015.5.03.0000, observa-se que a matéria levada ao Pleno do TST originalmente competia à adequação da via eleita (dissídio coletivo de natureza jurídica) em face da vedação contida na OJ 7 da SDC do TST, tese para qual o Ministro Ives Gandra Martins Filho havia aberto divergência. 
Considerando que a matéria conduzida ao plenário versava sob o aspecto processual da decisão, talvez seja preciso analisar com maior vagar como tal julgado pode ter superado, na dimensão material, a orientação anterior da SDC.

No entanto, é preciso analisar se é possível que a aplicação do texto legal seja interpretada sem qualquer interferência dos princípios.

\section{A força dos princípios nas relações privadas}

Como indicado no ponto anterior, tanto a decisão proferida pelo Presidente do Tribunal Superior do Trabalho, Ministro Ives Gandra Martins Filho, tanto o posicionamento adotado por Estevão Mallet convergem no sentido de que a aplicação de princípios constitucionais do Direito não seria suficiente a justificar a restrição à despedida.

Nesse sentido, aqui se traz a crítica tecida por Estevão Mallet (2017), ao discorrer sobre o tema, em trecho que cita a obra de Jorge Reis Novais:

O que se nota, na situação concreta, é que os princípios, especialmente o da dignidade da pessoa humana, são utilizados de maneira "meramente retórica", aproveitando-se de sua maior indeterminabilidade para os instrumentalizar "em favor de concepções particulares não consensualmente partilhadas que se procuram impor coercitivamente".

Por sua vez, nota-se na decisão proferida pelo Ministro Ives Gandra Martins Filho pouco apreço ao argumento da força dos princípios constitucionais positivos, como se observa no trecho a seguir:

[...] A hipótese é de nítido ativismo judiciário, contrário ao pilar básico de uma democracia, da separação entre os Poderes do Estado. Com efeito, em que pese por décadas, desde que a Constituição Federal de 1988 foi editada, demissões plúrimas se darem, apenas em 2009, em precedente da SDC, calcado em princípios gerais constitucionais, é que se passou a exigir, mesmo sem lei específica, a negociação coletiva prévia às demissões plúrimas. [...]

(TST. CorPAr-1000011-60.2018.5.00.0000. Relator: Ministro Ives Gandra Martins Filho, DJT 11.01.2018)

Do exposto, faz-se necessário analisar em que medida os referidos princípios de matriz constitucional vinculam a interpretação judicial, a partir da análise do seu conteúdo.

Embora se concorde em parte com o posicionamento do eminente professor Estevão Mallet (2017), não se pode imaginar que o princípio da dignidade da pessoa humana não possua qualquer aplicabilidade ao caso em questão. Malgrado a simples indicação da 
dignidade da pessoa humana não sirva à fixação do como proceder no caso em concreto, possui eficácia em face de qualquer ato que não realize o seu conteúdo, ou que torne mais difícil a sua realização.

Se não tivesse qualquer conteúdo normativo, poderia ser utilizado como argumento em sentido inverso, ou seja, serviria também a fundamentar a realização das despedidas coletivas. Mas não se encontra nenhum autor que entenda que tal (dignidade) legitima o encerramento do contrato por iniciativa do empregador, cujo esteio seria principalmente a autonomia privada.

Não se pretende que o debate reste apenas no plano dos efeitos da dignidade da pessoa humana. A partir da análise da discussão sobre a matéria, observa-se que o verdadeiro argumento de fundo é saber se a despedida, entendida como ato potestativo do empregador, pode ser limitada em sua dimensão coletiva.

Curiosamente, as posições em comento não enfrentam justamente aqueles que se entende serem o mais forte dos argumentos a limitar o exercício da despedida coletiva, que são os deveres de socialidade e boa-fé, oriundos do Direito Civil e de aplicação obrigatória nos atos da vida privada.

\section{4 - Os deveres de socialidade e boa-fé}

Discorrendo sobre o tema da boa-fé, Clóvis V. do Couto e Silva (2006, p. 22) indica que há sistemas jurídicos que adotam o nexo finalístico como posição relevante à formação dos atos da vida privada. Nesses sistemas, a autonomia não possui caráter absoluto, mas sim voltado à realização de um objetivo. Para o Autor, o dever que promana e boa-fé é o dever de consideração para com o outro.

Tratando da formação dos contratos, defende na sua tese que "a faculdade de determinar o conteúdo do negócio jurídico pode ser restringida em razão do desnível do poder econômico" (SILVA, 2006, p. 37), hipótese facilmente encontrada nas relações de trabalho. Ao tempo em que tal tema não se encontrava regulado pelo Código Civil, o Autor já defendia a aplicação da boa-fé como proposição fundamental de direito, independente da sua positivação.

O efeito do pensamento de Clóvis do Couto e Silva no ordenamento brasileiro pode ser traduzido pela positivação do artigo 422 do Código Civil, de que os contratantes devem guardar os princípios de probidade e boa-fé na conclusão do contrato. 
Por sua vez, Judith Martins-Costa (2015, p. 262) traça importante distinção entre a boa-fé subjetiva, que é descrita como o agir psicológico contrário a estar de má-fé, na qual o sujeito "tem a convicção, ainda que errônea, de estar a respeitar o Direito".

Já a boa-fé objetiva corresponde não só a um princípio, mas a um standart ou modelo, por meio do qual os participantes devem ajustar o seu comportamento, para assegurar as expectativas que formam o contrato (MARTINS-COSTA, 2015. p. 263). Assim, defende Clóvis do Couto e Silva (2006, p. 40) que existe um dever bilateral de proteção, que impede que uma das partes cause à outra um dano, em razão da sua atividade. Trata-se de efetivo limite à autonomia privada, razão pela qual mesmo direitos potestativos possuem restrições dadas pelo ordenamento.

Destaque-se que reconhecer que um direito é potestativo implica apenas indicar que não corresponde a um direito a uma prestação. Não se pode imaginar que tal característica de forma do ato possa indicar que os direitos potestativos sejam absolutos, arbitrários ou que possam ser exercidos de forma ilícita, ou seja, independentemente do seu conteúdo.

No presente estudo, se remete a essa definição de boa-fé objetiva, que parece ter sido a que foi positivada em nosso ordenamento. Tal postulado, por sua vez, é completado pelo dever de socialidade.

Na exposição de motivos do Código Civil de 2002, Miguel Reale (NOVO CÓDIGO CIVIL, 2005, p. 27), em carta remetida ao então Ministro da Justiça, Armando Falcão, expõe com clareza os pressupostos metodológicos que conduziram a elaboração do texto legal, para indicar a escolha pelos princípios da "socialidade" e "concreção" como balizas da construção do Código:

Não se compreende, nem se admite, em nossos dias, legislação que, em virtude da insuperável natureza abstrata das regras de direito, não abra prudente campo à ação construtiva da jurisprudência, ou deixe de prever, em sua aplicação, valores éticos, como os de boa-fé e eqüidade.

Discorrendo sobre a criação do texto de 2002 e o processo de codificação civil, Mario Luiz Delgado (2011, p. 296) aduz que “o princípio da socialidade, que não se confunde com 'socialismo', significa significa a prevalência dos valores coletivos sobre os individuais, mas sempre observando a pessoa humana e sua dignidade como valor fundante do ordenamento".

Enquanto a regra de concreção corresponde ao reconhecimento do Código enquanto estrutura plástica, ou seja, que comporta modificações em face dos processos hermenêuticos, 
a finalidade social do contrato é indicada como verdadeiro limite ao exercício da vontade, indicando a impossibilidade de reconhecer liberdades absolutas no campo negocial:

c) Tornar explícito, como princípio condicionador de todo o processo hermenêutico, que a liberdade de contratar só pode ser exercida em consonância com os fins sociais do contrato, implicando os valores primordiais da boa-fé e da probidade. Trata-se de preceito fundamental, dispensável talvez sob o enfoque de uma estreita compreensão positivista do Direito, mas essencial à adequação das normas particulares à concreção ética da experiência jurídica.

(NOVO CÓDIGO CIVIL, 2005, p. 42)

Da integração desse postulado com o texto constitucional, observa-se que o dever de socialidade possui lastro no artigo 170 da CF de 1988, que disciplina que a ordem econômica possui como finalidade principal assegurar a função social da propriedade e a busca pelo pleno emprego.

Conforme leciona Cláudio Luiz Bueno de Godoy (2007, p. 118), a partir da socialidade "tenciona-se retirar da lei civil do individualismo típico do modelo liberal", pensamento representado que representado no texto contido no artigo 421 do Código Civil.

Em verdade, tanto a socialidade quanto a boa-fé estão diretamente relacionados. $\mathrm{Ou}$ seja: o dever de socialidade, previsto no anteprojeto, se realiza no direito positivo também através da boa-fé objetiva e da probidade.

Assim, compete ao Código Civil o fechamento interpretativo da proposta em questão, a demonstrar que as relações privadas, em que pese marcadas por uma relativa autonomia, também se submetem igualmente ao dever de atender à finalidade social do direito.

No entanto, não se pode imaginar que o dever de socialidade seja uma construção apenas do Código Civil de 2002, nem que sua aplicação seja restrita ao âmbito das relações civis. Isso porque o mesmo dever se encontra no artigo $5^{\circ}$ da Lei de Introdução às normas do Direito Brasileiro (Decreto-Lei no 4.657/1942).

Justificando tal artigo, defende Cláudio Luiz Bueno de Godoy (2007, p. 130) que o solidarismo não interessa apenas aos contratantes, mas a toda a sociedade. De fato, se o objetivo final da socialidade é alcançar a igualdade entre os contratantes, aponta o Autor ser objetivo que todas as partes tenham igualmente autonomia, e não apenas uma delas:

O solidarismo social ostenta um primeiro contorno, que vale para qualquer das relações jurídicas, paritárias ou não, de, justamente, preservar uma substancial igualdade entre as pessoas, garantindo que suas contratações sejam justas e, mais, 
marcadas pelo padrão de exigência de colaboração entre os contratantes, assim socialmente utéis.

Frise-se que também a jurisprudência já se firmou no sentido de que a boa-fé é aplicável a todas as relações privadas. Nesse sentido, é conveniente destacar o recente julgado do STJ no REsp 1363814/PR, de relatoria do Ministro MOURA RIBEIRO, julgado em 17/10/2017, no qual a regra de eticidade prevaleceu sobre a disposição contratual de atualização cambiária.

No âmbito do TST, a mesma tese se mostra presente nos julgamentos, como se infere do julgado sob a relatoria do Ministro Cláudio Brandão no processo AIRR - 16650091.2009.5.06.0020, de 13 de dezembro de 2017, no qual a cláusula geral de boa-fé objetiva é o principal fundamento da decisão.

Logo, é papel do Estado exigir a observância a tais princípios, seja no âmbito das relações cíveis ou das relações de trabalho. Em verdade, inexiste relação jurídica privada que prescinda do dever de eticidade e socialidade dos contratos.

\section{5 - Aplicação da socialidade e boa-fé ao encerramento dos contratos de trabalho}

Como indica Carlyle Popp apud Cláudio Luiz Bueno de Godoy (2007, p. 118), “a função social do contrato representa um mecanismo interventivo da diminuição da desigualdade para, com isso, aumentar-se a liberdade real dos contratantes".

Destaque-se que o dever de observância da boa-fé objetiva constou do voto do Ministro Maurício Godinho Delgado na decisão da SDC de 2009, malgrado tenha sido voto vencido no julgamento. Embora o tema já tenha sido julgado no TST, é conveniente que se retorne à sua discussão, uma vez que o fundamento fático atual não é o mesmo observado em 2009.

É que na definição clássica de Orlando Gomes (1974, p. 575) exige-se que a despedida coletiva não tenha por objetivo a substituição dos contratos de trabalho. Mas, nos recentes casos levados aos Tribunais, não se cuida do encerramento das atividades do empregador, e sim da expectativa de contratação de outros ou dos mesmos trabalhadores sob a vigência de novas regras de trabalho, inauguradas pela Lei 13.467/2017. Tecnicamente falando, não se cuida de verdadeira despedida coletiva.

Trata-se de hipótese anteriormente não imaginada no ordenamento, de que uma das partes pode, unilateralmente, romper o contrato para forçar a sua revisão. No caso, não se 
pode falar em denúncia vazia, mas sim em encerramento motivado, fundado no interesse de modificar o contrato.

Assim, cumpre tornar debater o dever de boa-fé, para analisar se tal exigência efetivamente se aplica à terminação dos contratos de trabalho. Por certo, algo que se repute como abusivo no âmbito do Direito Civil certamente não será reconhecido como válido no âmbito do Direito do Trabalho, que demanda maior intervenção.

Não se imagine que o conteúdo de boa-fé seja meramente abstrato no âmbito das relações de trabalho. Discorrendo sobre o tema, Judith Martins-Costa (2015, p. 308) defende que "há para ambos, empresa e empregado, deveres de consideração, coerência comportamental e de proteção", como vedação ao exercício desleal de qualquer das partes.

Por esse motivo, o que tais atos praticados pelo empregador implicam é, em última ratio, na rediscussão do conteúdo objetivo do contrato, feita a partir da imposição do poder econômico. Não há indicativo, ao menos nos processos em questão, de que o empregador tenha decidido se retirar da vida social.

Se o objetivo da terminação do contrato é rever os seus termos, não se fala em direito ao seu encerramento unilateral, mas sim do dever de observância dos termos para negociação. No Brasil, a negociação coletiva de contratos se dá com a participação dos sindicatos, no que é denominado princípio da interveniência sindical obrigatória, na forma do artigo $8^{\circ}$, VI, da $\mathrm{CF} / 88$.

Considerando o sistema brasileiro, é possível apontar que a Constituição Federal condiciona a maior liberdade na estipulação das regras do contrato de trabalho ao atendimento de forma preestabelecida, correspondente à negociação coletiva.

Justamente por esse motivo, parte considerável da doutrina defende a conceituação da negociação coletiva sob a perspectiva procedimental. Para Amauri Mascaro Nascimento (2003, p. 432), “a negociação coletiva é uma série de atos, de tratos seguidos entre os protagonistas de uma disputa coletiva, para discussão das reivindicações formuladas por uma das partes a outra".

O mesmo entendimento é compartilhado por Luciano Martinez (2013), que defende que "é uma ação, um procedimento por meio". Para Henrique Macedo Hinz (2009, p.100), “a negociação coletiva é um processo cuja finalidade é, por meio de concessões recíprocas entre os representantes do capital e do trabalho, a celebração de acordos ou convenções coletivas de trabalho". 
Tal permite concluir que a possibilidade de revisão dos contratos de trabalho se encontra limitada, no Direito brasileiro, pelos requisitos próprios da negociação coletiva, que exige sempre a participação das entidades sindicais de trabalhadores.

A luz das definições aqui transcritas, se defende como hipótese que o dever de boa-fé e socialidade representa limitação à atuação das partes não somente no momento da contratação, mas também no momento do encerramento do contrato. Com efeito, não se pode admitir como jurídica a conduta de uma das partes que tenha por objetivo impor a vontade de um dos contratantes às demais partes, mormente com uso do poder econômico.

Em sentido analógico, é conveniente destacar que a Lei 7.783/89 (Lei de Greve) expressamente veda conduta decorrente do abuso de poder econômico, que é o lock-out, conforme a previsão do seu artigo 17.

Trata-se de exemplo claro de limitação de um direito potestativo (manter a empresa em funcionamento) que se observa em razão da motivação apresentada pelo empregador (frustar negociação coletiva). Ao vedar a paridade de armas, no presente caso, buscou o legislador assegurar que as partes se igualassem, em sentido material e não apenas formal, também nas relações coletivas.

Se a atividade do empregador não pode ser paralisada quando implicar restrição ao direito de negociar coletivamente, como se poderia reconhecer validade no encerramento dos contratos que visa rediscutir os seus termos, mas sem a participação dos sindicatos? Se o direito disciplina a formação dos contratos, dentro de um dever de eticidade, não pode jamais deixar de tutelar a sua extinção.

De forma ainda mais específica, na redação do anteprojeto do Código Civil de 2002, entendeu Miguel Reale Reale (NOVO CÓDIGO CIVIL, 2005, p. 44) ser necessário limitar o instituto da denúncia vazia nos contratos por tempo indeterminado, com o fito de coibir o abuso do poder econômico. Em que pese o enfoque do Direito Civil, a mesma preocupação se mostra pertinente ao Direito do Trabalho, em que a assimetria das partes é tida como regra:

u) Limitação do poder de denúncia unilateral dos contratos por tempo indeterminado, quando exigidos da outra parte investimentos de vulto, pressupondo ela poder dispor de prazo razoável, compatível com as despesas feitas. Esta sugestão, por mim feita e acolhida pela Comissão, é um dos tantos exemplos da preocupação que tivemos no sentido de coarctar os abusos do poder econômico.

No particular, não se pode concordar com a afirmação feita por Enoque Ribeiro dos Santos (2017), segundo a qual a denúncia vazia do contrato de trabalho pode ser feita nos Estados Unidos sem qualquer tipo de restrição. 
Ocorre que mesmo o At-will employment possui três exceções, como informa Charles J. Mull (2001) em pesquisa sobre o tema. Em regra, não se aceita a extinção do contrato de trabalho que viole alguma política pública, como o combate à discriminação. Também não se aceita o encerramento unilateral se houver previsão contratual de garantia da segurança do emprego. E por fim, o dever de observar a boa-fé no encerramento do contrato corresponde a terceira exceção, permitindo a sua desconstituição toda vez que restar provado que decorreu de motivo torpe ou sem justificativa.

Ora, se há um dever de ambas as partes em uma relação jurídica de buscar a realização dos objetivos que motivaram a formação do contrato, a possibilidade de extinção contratual unilateral já configura uma exceção a tal regra. Diante das particularidades do Direito do Trabalho, a teoria do risco do negócio e o papel do direcionamento dado pelo empregador já exigem algum tipo de proteção do trabalhador quando do encerramento do contrato.

Considerando que, em tese não interessa à qualquer das partes o fomento do desemprego, é papel de ambas as partes na relação de trabalho buscar mecanismos para a manutenção dos contratos de trabalho. Nesse sentido é que se indica que a negociação coletiva se faz necessária, uma vez que a autonomia privada coletiva pode alcançar mecanismos que evitem a extinção dos contratos.

Não há que se cogitar que a exigência de negociação, de caráter bilateral, possa ser vista como vantajosa a apenas uma das partes. Ao exigir que haja negociação coletiva, demanda-se que todos os contratantes, por meio do ente juridicamente legitimado para tanto, empreendam esforços destinados a alcançar um objetivo comum.

No âmbito da comparação de institutos jurídicos, pode se notar a adoção de soluções semelhantes em outros países. Aqui se toma como exemplo a Rússia, país que possui níveis econômicos no plano internacional que são semelhantes aos do Brasil. Segundo relatório elaborado pela OIT (2001) nesse país, as despedidas em massa, decorrentes dos processos de privatização em meados dos anos 1990, tiveram como consequência direta o aumento das taxas gerais de desemprego, redução do poder de compra dos salários e aumento da desigualdade social.

Nesse país, observou-se que a temática da dispensa coletiva passou a ser regida por meio de negociações coletivas, com o intento de gerar proteção social aos trabalhadores e promover mecanismos para a criação de novos empregos (OIT, 2001, p. 66-70). 
O estudo em questão conclui que, em momentos de crise, faz-se necessário que a negociação coletiva seja estimulada, como forma de manter os empregos e superar as adversidades econômicas. Na maior parte dos países da Europa, outro relatório da OIT (2010) indica que a despedida em massa em regra demanda negociação coletiva.

O que se pode inferir do referido documento é que a negociação coletiva permitiu a customização das despedidas em massa, atendendo às necessidades dos empregadores e dos empregados. Considerando que a criação do texto normativo da Lei 13.467/2017 indica a existência de crise como fundamento para a alteração legislativa, é de se questionar a razão pela qual o Brasil seguiu um caminho diferente da experiência de outros países.

\section{CONCLUSÃO}

A nova disciplina legal da dispensa coletiva não dispensa a sua interpretação à luz das normas que informam o ordenamento jurídico, em especial, a boa-fé e o dever de socialidade. Considerando o papel que esses princípios exercem em todas as relações privadas, não se cogita que um ato, ainda que potestativo, possa ser pratico em desconformidade com as regras do artigo 421 e 422 do Código Civil.

Por outro lado, se o objetivo do encerramento do contrato é meramente a sua rediscussão, sob parâmetros menos favoráveis aos trabalhadores, necessário se faz que tal se dê por intermédio da negociação coletiva, evitando que tal ato implique em abuso do poder econômico.

Em razão do papel do Estado de assegurar a igualdade nas relações jurídicas, não se pode reconhecer a faculdade unilateral do empregador de encerrar os contratos de trabalho de forma coletiva, notadamente nos momentos em que se enfrentam quadros de crise econômica.

\section{REFERÊNCIAS}

\section{BRASIL. DECRETO-LEI N 4.657, DE 4 DE SETEMBRO DE 1942.}

BRASIL. Novo código civil : exposição de motivos e texto sancionado. 2 ed. Brasília : Senado Federal, Subsecretaria de Edições Técnicas, 2005. Disponível em: $<$ http://www2.senado.leg.br/bdsf/handle/id/70319 >. Acesso em 25 jan. 2018.

BRASIL. STJ, REsp 1363814/PR, Rel. Ministro MOURA RIBEIRO, TERCEIRA TURMA, julgado em 17/10/2017, DJe 30/10/2017. 
BRASIL. TRT-1 - Recurso Ordinário RO 16183920125010023 RJ, TRT-4 - Recurso Ordinário RO 00010749420115040381.

BRASIL. TST ED-RODC - 30900-12.2009.5.15.0000. Data de Julgamento: 10/08/2009, Relator Ministro: Mauricio Godinho Delgado, Seção Especializada em Dissídios .Coletivos, Data de Publicação: DEJT 04/09/2009.

BRASIL. TST. CorPAr-1000011-60.2018.5.00.0000. Relator: Ministro Ives Gandra Martins Filho, DJT 11.01.2018.

BRASIL. TST. CorPar $\mathbf{N}^{\mathbf{0}}$ 1000393-87.2017.5.00.0000. Relator: Ministro Ives Gandra Martins Filho, DJT 08.01.2018.

BRASIL. TST. AIRR - 166500-91.2009.5.06.0020, Relator Ministro: Cláudio Mascarenhas Brandão, Data de Julgamento: 13/12/2017, 7ª Turma, Data de Publicação: DEJT 19/12/2017.

DELGADO, Mario Luiz. Codificação, descodificação e recodificação do direito civil brasileiro. São Paulo: Saraiva, 2011.

GODOY, Cláudio Luiz Bueno de. Função social do contrato: os novos princípios contratuais. 2. ed. rev e atual. São Paulo: Saraiva, 2007.

GOMES, Orlando. Dispensa coletiva na reestruturação da empresa - Aspectos jurídicos do desemprego tecnológico. São Paulo: LTr, 1974.

HINZ, Henrique Macedo. Direito Coletivo do Trabalho - 2 ed. rev e atual. São Paulo: Saraiva, 2009.

INSTITUTO VIA JURIS. INSTITUTO VIA IURIS COMPARTILHA NOVOS OLHARES SOBRE A REFORMA TRABALHISTA COM DEPUTADO RELATOR. São Paulo, 5 de abril de 2017. Disponível em http://www.institutoviaiuris.org.br/instituto-via-iuris-compartilhanovos-olhares-sobre-a-reforma-trabalhista-com-deputado-relator/, acesso em 20.01.2018.

MALLET, Estêvão. Dispensa coletiva e negociação sindical. Revista da Faculdade de Direito, Universidade de São Paulo, São Paulo, v. 111, p. 123-142, june 2017. ISSN 23188235. Disponível em: 〈https://www.revistas.usp.br/rfdusp/article/view/133497>. Acesso em: 03 feb. 2018. doi:http://dx.doi.org/10.11606/issn.2318-8235.v111i0p123-142.

MARTINS-COSTA, Judith. A boa-fé no direito privado: critérios para sua aplicação. São Paulo: Marcial Pons, 2015.

MARTINEZ, Luciano. Condutas Antissindicais. São Paulo: Saraiva, 2013.

MARTINEZ, Luciano. Curso de Direito do Trabalho: relações individuais, sindicais e coletivas de trabalho. 7. ed. São Paulo: Saraiva, 2016.

MORAES, Ricardo. Estácio de Sá demite 1,2 mil professores após reforma trabalhista. Folha de São Paulo. São Paulo, 5 de dezembro de 2017. Disponível em 
http://www1.folha.uol.com.br/mercado/2017/12/1940980-estacio-de-sa-demite-12-milprofessores-apos-reforma-trabalhista.shtml, acesso em 22.12.2017.

MULH, Charles J. The employment-at-will doctrine: three major exceptions. Monthly Labor Review: January 2001. Disponível em:

<https://www.bls.gov/opub/mlr/2001/01/art1full.pdf>. Acesso em 02.02.2018.

NASCIMENTO, Amauri Mascaro. Compëndio de Direito Sindical. São Paulo: LTr, 2003.

OIT, Labour market flexibility and employment security. 2001. Disponivel em: $<$ http://www.ilo.org/wcmsp5/groups/public/---

ed_emp/documents/publication/wcms_142362.pdf >

Acesso em 02.02.2018.

OIT. Negotiating the crisis? collective bargaining in Europe during the economic downturn / Vera Glassner and Maarten Keune ; International Labour Office. - Geneva: ILO, 20101 v. p. (DIALOGUE working paper ; no.10) ISBN: 9789221233268;9789221233275

(web pdf). Disponível em: <http://www.ilo.org/wcmsp5/groups/public/---ed_dialogue/--dialogue/documents/publication/wcms 158354.pdf $>$. Acesso em: 01.02.2018.

REVISTA VIA JURIS. Disponível em http://www.institutoviaiuris.org.br/wpcontent/uploads/2017/03/Reviata via iuris reforma Trabalhista.pdf, acesso em 20.01.2018.

RIBEIRO DOS SANTOS, Enoque. A dispensa coletiva na Lei n. 13.467/2017 da Reforma Trabalhista. Disponível em: <http://genjuridico.com.br/2017/07/26/dispensa-coletiva-na-lein-13-4672017-da-reforma-trabalhista/>. Acesso em: 20 jan 2018.

SILVA, Clóvis do Couto e. A obrigação como processo. Reimpressão. Rio de Janeiro: Editora FGV, 2006. 